Srivastava, Rajendra. (2003) A Conceptual Framework and Belief-Function Approach to Assessing Overall Information Quality. International Journal of Intelligent Systems, 18 (1), 51-74. Publisher's Official Version: <http://onlinelibrary.wiley.com/journal/ 10.1002/\%28ISSN\%291098-111X>. Open Access Version: <http://kuscholarworks.ku.edu/dspace/>.

[This document contains the author's accepted manuscript. For the publisher's version, see the link in the header of this document.]

\title{
A Conceptual Framework and Belief-Function Approach to Assessing Overall Information Quality
}

\author{
By Matthew Bovee, Rajendra P. Srivastava, and Brenda Mak
}

The University of Kansas, The University of Kansas, and San Francisco State University

\section{Paper citation:}

Srivastava, Rajendra. (2003) A Conceptual Framework and Belief-Function Approach to

Assessing Overall Information Quality. International Journal of Intelligent Systems, 18 (1), 51-74.

\section{Keywords:}

\author{
Information Quality, Belief Functions, and Aggregation of Evidence
}

\begin{abstract}
:
We develop an information quality model based on a user-centric view adapted from Financial Accounting Standards Board1, Wang et al.2, and Wang and Strong3. The model consists of four essential attributes (or assertions): 'Accessibility,' 'Interpretability,' 'Relevance,' and 'Integrity.' Four sub-attributes lead to an evaluation of Integrity: 'Accuracy,' 'Completeness,' 'Consistency,' and 'Existence.' These sub-attributes relating to 'Integrity' are intrinsic in nature and relate to the process of how the information was created while the first three attributes: 'Accessibility,' 'Interpretability,' and 'Relevance' are extrinsic in nature. We present our model as an evidential network under the belief-function framework to permit user assessment of quality parameters. Two algorithms for combining assessments into an overall IQ measure are explored, and examples in the domain of medical information are used to illustrate key concepts. We discuss two scenarios, 'online-user' and 'assurance-provider,' which reflect two likely and important aspects of IQ evaluation currently facing information users - concerns about the impact of poor quality online information, and the need for information quality assurance.
\end{abstract}




\title{
A Conceptual Framework and Belief-Function Approach to Assessing Overall Information Quality
}

\author{
Matthew Bovee \\ Doctoral Student \\ School of Business \\ The University of Kansas \\ Lawrence, KS 66045 \\ mbovee@ukans.edu
}

\author{
Rajendra P. Srivastava \\ Ernst \& Young Distinguished Professor and Director \\ Ernst \& Young Center for Auditing Research and Advanced Technology \\ School of Business \\ The University of Kansas \\ Lawrence, KS 66045 \\ rsrivastava@ku.edu
}

and

\section{Brenda Mak}

Assistant Professor

San Francisco State University

San Francisco, CA

bmak@sfsu.edu 


\title{
A Conceptual Framework and Belief-Function Approach to Assessing Overall Information Quality
}

\begin{abstract}
We develop an information quality model based on a user-centric view adapted from Financial Accounting Standards Board ${ }^{1}$, Wang et al. ${ }^{2}$, and Wang and Strong ${ }^{3}$. The model consists of four essential attributes (or assertions): 'Accessibility,' 'Interpretability,' 'Relevance,' and 'Integrity.' Four sub-attributes lead to an evaluation of Integrity: 'Accuracy,' 'Completeness,' 'Consistency,' and 'Existence.' These sub-attributes relating to 'Integrity' are intrinsic in nature and relate to the process of how the information was created while the first three attributes: 'Accessibility,' 'Interpretability,' and 'Relevance' are extrinsic in nature. We present our model as an evidential network under the belief-function framework to permit user assessment of quality parameters. Two algorithms for combining assessments into an overall IQ measure are explored, and examples in the domain of medical information are used to illustrate key concepts. We discuss two scenarios, 'online-user' and 'assurance-provider,' which reflect two likely and important aspects of IQ evaluation currently facing information users - concerns about the impact of poor quality online information, and the need for information quality assurance.
\end{abstract}

Key words: Information Quality, Be lief Functions, and Aggregation of Evidence 


\section{A Conceptual Framework and Belief-Function Approach to Assessing Overall Information Quality}

\section{INTRODUCTION}

We work in an information economy ${ }^{4}$, interact in an information society, and live in an information world ${ }^{5}$. Identification and management of corporate information has become a specialized business sub-discipline, but availability of information alone is no longer a strategic advantage - quality of information is ${ }^{6}$. We often implicitly depend on the quality of information we use in decisions, yet poor quality information is often cited as a source of lost productivity or failed enterprise $e^{3,6,7,8,9}$. The quality of information on the Internet is of great concern ${ }^{10}$ and its uncritical use poses serious risks. Biermann et al. ${ }^{11}$ and Silberg et al. ${ }^{12}$ cite glaring omissions and inaccuracies in online medical information.

Yet, despite its importance and value, the quality of information from many contexts is often variably or loosely defined or simply ignored ${ }^{3,13,14,15}$. A means to assess information quality (IQ) for decision-making is vital. Without clearly defined attributes and their relationships, we are not just unable to assess IQ; we may be unaware of the problem. We need to understand the attributes of IQ and to have a broadly applicable, meaningful way to combine evaluations of them into a single quality measure. Unfortunately, various problems with pre-existing IQ models hinder this: limitation to a specific view of information or quality, missing attributes, and confusion or dependence between attributes and sub-attributes. For example, one well-known product-oriented IQ model by Wang and Strong ${ }^{3}$ presents a key IQ attribute of Believability, with a sub-attribute of source credibility. Yet something credible is defined as having sufficient evidence to be believed, and thus there is circularity between the levels. Also, since evidence of source credibility may be assessed without examining information itself, any weight placed on credibility occurs at the wrong le vel in the model.

Another, systems-oriented IQ model by Wand and $\mathrm{Wang}^{7}$ evaluates many intrinsic aspects of information completeness and consistency, but fails to include an attribute such as 'existence', an important attribute of information from auditing (e.g., see Mautz and Sharaf ${ }^{6}$ ). Information meeting the test of existence is neither false nor redundant. For example, a hospital's 
Srivastava, Rajendra. (2003) A Conceptual Framework and Belief-Function Approach to Assessing Overall Information Quality. International Journal of Intelligent Systems, 18 (1), 51-74. Publisher's Official Version: <http://onlinelibrary.wiley.com/journal/ 10.1002/\%28ISSN\%291098-111X>. Open Access Version: <http://kuscholarworks.ku.edu/dspace/>.

patient record database would violate an 'Existence' attribute if it contained: 1) records for nonexistent patients, 2) redundant (i.e. wrongly repeated or duplicate) patient records, 3) fictitious fields or 4) fictitious values for valid fields.

What is needed is an IQ model flexible enough to work across various domains and purposes of users' interests, robust enough to capture criteria from the information production process of interest and of importance to users, and with clearly defined theoretical constructs as dimensions for testing against the perceptions of information users. A means of combining evaluations assigned to IQ attributes is also needed.

The main purpose of this paper is to develop such a conceptual model for assessing IQ, with all its essential dimensions or attributes that determine the quality, in any domain. We incorporate features of other key IQ models (e.g., Financial Accounting Standards Board ${ }^{1}$ (FASB); Wang et al. ${ }^{2}$; Wang and Strong ${ }^{3}$ ) along with addressing and resolving their pre-existing problems. We detail and address the problems highlighted above, and additional problems of the models, in Section III. Since assessing information quality is a process of gathering items of evidence pertaining to each attribute (dimension) of IQ and aggregating them to make an overall judgment, we develop the IQ assessment model using the evidential network approach of Srivastava et al. $^{17}$ (see also Srivastava and Mock $^{18}$ ) under the belief-function framework. In general, an item of evidence pertaining to an IQ attribute has associated uncertainty - we can never be sure that an item of evidence fully assures that the attribute is met. In such a situation, we need a framework to represent the associated uncertainty. As argued by Srivastava and Shafer ${ }^{19}$ and empirically tested by Harrison et $\mathrm{al}^{20}$ (see also Curley and Golden ${ }^{21}$ ) in an auditing context, the belief-function framework provides a broader framework for representing uncertainties in evidence, especially when the evidence provides only one-sided support; i.e., the evidence either supports or refutes the attribute. It is not easy to represent such evidence in the probability framework. Moreover, the probability framework is a special case of the belieffunction framework (Shafer and Srivastava ${ }^{22}$ ).

Thus, this paper presents a simple and intuitive framework that incorporates features of other key IQ models and addresses pre-existing problems of interdependence, omission and confusion within dimensions. The model is then described as an evidential network under the belief-function framework for explicitly tracking the support levels obtained from items of 
evidence pertaining to various IQ attributes or assertions and combining them into an overall IQ assessment. We discuss two scenarios, 'online-user' and 'assurance-provider,' which reflect two likely and important aspects of IQ evaluation currently facing information users - concerns about the impact of poor quality online information, and the need for information quality assurance.

The remaining sections of the paper are as follows: Section II briefly reviews information, quality, and IQ definitions; Section III describes our proposed IQ model and its extensions relative to key IQ models; Section IV describes our IQ model as an evidential network; Section V describes sensitivity analyses performed on the network and Section VI discusses their results; Section VII presents conclusions and directions for future research. Appendices A and B provide brief reviews of Belief Functions and Auditor's Assistant, the software used in sensitivity analysis.

\section{INFORMATION, QUALITY, AND INFORMATION QUALITY}

In this section we discuss the definitions used for information, quality, and information quality, and present a categorization of information quality views and models.

\section{Information}

The origin of the word data is a Latin noun, datum, meaning something that is given. An alternate definition is facts or pieces of information. "Inform" means to give form or character 23 . Thus we use the definition that information is ${ }^{23}$, or contains ${ }^{5}$, input or pieces of information (data) organized to some purpose. Throughout the paper we treat data and information synonymously ${ }^{24}$.

There are at least six different schools of thought regarding information (Table 1). Each embodies the concept of information as a signal with senders and receivers ${ }^{24,25}$, and each is consistent with our treatment of information created from structured input or data.

\section{Insert Table 1 here}

Some information definitions (e.g. Davenport and Prusak ${ }^{23}$ ) invoke fitness for the user's purpose to discriminate data from information. This invites confusion between structured information, which is stable across user contexts ${ }^{5}$, and its usefulness. Input needs to be organized 
Srivastava, Rajendra. (2003) A Conceptual Framework and Belief-Function Approach to Assessing Overall Information Quality. International Journal of Intelligent Systems, 18 (1), 51-74. Publisher's Official Version: <http://onlinelibrary.wiley.com/journal/ 10.1002/\%28ISSN\%291098-111X>. Open Access Version: <http://kuscholarworks.ku.edu/dspace/>.

to some purpose to be information, but not necessarily a specific purpose nor that defined by a given $u^{24}{ }^{24}$. Fitness of use for the domain and purpose of interest to the user defines information quality, not information. Otherwise, we should recognize "useless information" as an oxymoron.

\section{Quality}

There is long-standing support for the user-centric, product-oriented approach to defining quality (see, e.g., Deming ${ }^{26}$, Garvin ${ }^{27}$, Juran ${ }^{28}$, Wang and Strong ${ }^{3}$, and Huang et al. ${ }^{6}$ ), and there is intuitive simplicity in it. Fitness of use as an IQ definition also has an additional advantage. Since information is highly fungible - the same information may be used by consumers with widely variant purposes and grossly dissimilar domains of interest - we need a highly flexible, yet consistent definition. Unlike other products where the quality can be uniquely defined ${ }^{27}$, information quality varies with the user's perspective. The same information may be of high quality for one user and be of low quality for another. For example, a list of names with mailing addresses in a given locality may be of high quality for a user who wants to mail advertisements for a consumer product but may be of low quality for a user who wants to contact all the medical doctors in the locality.

\section{Information Quality}

Just as there are multiple views regarding the concepts of information and quality, there are multiple views on what defines IQ or its dimensions as evidenced from information quality literature (see, e.g., FASB ${ }^{1}$, Wang et al. ${ }^{2}$, and Wang and Strong ${ }^{3}$ ). These tend to vary based on the definitional approach to quality (intrinsically or extrinsically defined) as well as the model of information (theoretical, system or process output, or product). Theoretical models ${ }^{2}$ define IQ conceptually based on introspection and logical analysis. Process-focused models (e.g. Kinney ${ }^{29}$ ) view information as a by-product of measurement. If the measurement process is accurate and properly applied according to user requirements, then the resulting output is expected to be quality information. System-focused models center on specifying the many views and formats involved in the collection, storage, retrieval and display of information ${ }^{25}$ such that the information that results from the process or the system should correctly represent the real-world view of interest to the user ${ }^{7}$. A user-centric model (e.g. Wang and Strong ${ }^{3}$ ) defines quality information as meeting user needs according to external, subjective user perceptions. 
Each of these views has its strengths and weaknesses. Theoretical models provide good explication of constructs and relationships aimed at describing users' needs and grounded in the literature, but they tend to treat quality as an objective construct, ignoring user perceptions. Systems- and process-oriented models tend to capture more details specific to intrinsic attributes of information, but view information as a process output or byproduct. User-centric models capture the broader range of attributes described as important by information consumers, but do not provide clearly defined constructs for these attributes. But, just as there are common dimensions for determining the quality of a type of wood for a given use, despite the plethora of types and uses available (e.g. grain, color, hardness, cost, rarity, etc.), general attributes applicable across domains and purposes of interest to information users may provide stable dimensions for assessing information quality.

\section{PROPOSED IQ MODEL}

In this section we describe our proposed model of information quality, its attributes, and their respective sub-attributes, relative to three other key IQ models: Financial Accounting Standards Board ${ }^{1}$, Wang et al. ${ }^{2}$, and Wang and Strong ${ }^{3}$. Since our reasoning and model closely parallel that of Wang et al. ${ }^{2}$, we especially note important differences with that model.

To determine and evaluate IQ attributes we take the view of an information user and outline what we require for an information product to be useful. To clarify attributes and subattributes of information quality, and any comparisons, explanatory examples are given from the domain of medical information. The model as depicted in Figure 1 may be summarized by a simple, ordered mnemonic of the main attributes: $\mathbf{A} \mathbf{I}_{\mathbf{1}} \mathbf{R} \mathbf{I}_{\mathbf{2}}-$ Accessibility, Interpretability, Relevance, and Integrity.

\section{----- Figure 1 -----}

Similar to Financial Accounting Standards Board ${ }^{1}$ and Wang and Strong ${ }^{3}$, we define quality of information here as a global assessment of its fitness for use. Wang et al. ${ }^{2}$ consider 'usefulness', but either misuse or misplace it in their model, since its location suggests that information might be inaccessible or unintelligible and yet still useful. Briefly, to determine the quality of information we must: 1) get information which we might find useful (Accessibility); 2) understand it and find meaning in it (Interpretability); 3) find it applicable to our domain and purpose of interest in a given context (Relevance); and 4) believe it to be free from defects 
Srivastava, Rajendra. (2003) A Conceptual Framework and Belief-Function Approach to Assessing Overall Information Quality. International Journal of Intelligent Systems, 18 (1), 51-74. Publisher's Official Version: <http://onlinelibrary.wiley.com/journal/ 10.1002/\%28ISSN\%291098-111X>. Open Access Version: <http://kuscholarworks.ku.edu/dspace/>.

(Integrity). We would dismiss or discount information that meets our criteria for all but one of any of the above attributes, each of which may be more than just a binary value.

\section{Accessibility}

We must first get information for it to be of use. Information accessibility is not included in the Financial Accounting Standards Board ${ }^{1}$ model, and rarely cited by IQ models that focus on information as a by-product of the system ${ }^{15}$. Yet, it is obviously critical to the user (see, e.g., Strong, et al. ${ }^{8}$, Wang et al. $^{2}$, Wang and Strong ${ }^{3}$ ). Information retrieval may require a certain amount of time or have an associated measure of cost to the user. If information is inaccessible, all other qualities of it are irrelevant.

A hospital medical report on the outcome of patient surgery may not be needed before the end of the month for statistical purposes, or it may be needed immediately for reference and review during an examination. Off-site, clinical access to such information may be free, available as for-pay products or services, or part of a private intranet. Even access to different in-house information sources within the same hospital may have widely different times and associated costs. Depending on their setting, a physician might conceivably have to decide between the results immediately on hand, those available by mail, by fax, or by electronic transfer, and the delays and costs associated with each choice.

\section{Interpretability}

Second, we must understand any information retrieved (it must be intelligible) and, if it is understandable, we must derive meaning from it. Intelligible information is capable of being understood by the user and meaningful information conveys to the user some sense, significance, or meaning. The Financial Accounting Standards Board ${ }^{1}$ discusses understandability as a necessary, overarching attribute of information, but their explanatory model makes it appear that information could be useful but not understandable. System-focused IQ models tend to assume interpretability of output information to be inherent in the correct specifications of the system, the database design or the data production process (Kinney ${ }^{29}$, Wang et al. ${ }^{15}$, Wand and Wang $^{7}$ ). While Wang et al. ${ }^{2}$ describe interpretability as the understandability of the syntax and semantics of information, we agree with Wang and Strong $^{3}$ that users requirements for interpretability of information may be much broader, ranging to practically requiring that "the thing speaks for 
Srivastava, Rajendra. (2003) A Conceptual Framework and Belief-Function Approach to Assessing Overall Information Quality. International Journal of Intelligent Systems, 18 (1), 51-74. Publisher's Official Version: <http://onlinelibrary.wiley.com/journal/ 10.1002/\%28ISSN\%291098-111X>. Open Access Version: <http://kuscholarworks.ku.edu/dspace/>.

itself $^{\prime 30}$. If, however, information is either unintelligible or meaningless to us, all its other qualities are irrelevant.

Unintelligible or meaningless information to one user may be intelligible or meaningful to another. The information content or structure has not changed, but its quality differs according to user-determined criteria. For example, the same patient's blood chemistry report could be written in two versions: English and Japanese. To a physician unable to read it, the Japanese report would be unintelligible and therefore meaningless, while to a phys ician fluent in both languages either report would be equally suitable. Intelligibility is a necessary but insufficient condition for interpretability. Consider the case in which a patient who wants to know the results of their medical check-up finds the clinical report to be intelligible (i.e. in readable English), but meaningless because they lack training or domain knowledge necessary to interpret the values.

\section{Relevance}

Third, given information we can understand and interpret, we want it to be relevant to our domain and purpose of interest in a given context. Criteria regarding the domain and purpose of interest are specific to the user, and determine the desired information pieces. A simple database example would be defining the structure of a desired table of records, and their attributes or 'fields'. Or, a surgeon planning an operation must assess a variety of clinical information (blood pressure, sensitivity to anesthesia, medications, etc.) about the patient for the purpose of performing that operation successfully. A full report of the correct patient's insurance and payment history meets neither the doctor's domain- nor purpose-specific information needs (the patient's clinical history for the purpose of pre-operative preparation). While a clinical dietician and a surgeon may both consider the patient's dietary history to be clinical information, it would not meet the surgeon's purpose-specific information needs (performing an operation as opposed to monitoring or managing dietary balance). A surgeon performing an operation in the field, under combat situations, may have a contextually altered set of domain- and purpose-specific information needs compared to one performing the same operation on the same patient in outpatient surgery. In each case, the information supplied may be 'Accessible' and 'Interpretable' but not relevant in terms of user-specified criteria. Although the Financial Accounting Standards Board ${ }^{1}$ model includes 'Relevance', its criterion that information must possess the capacity to influence decision-making is operationally synonymous with 
Srivastava, Rajendra. (2003) A Conceptual Framework and Belief-Function Approach to Assessing Overall Information Quality. International Journal of Intelligent Systems, 18 (1), 51-74. Publisher's Official Version: <http://onlinelibrary.wiley.com/journal/ 10.1002/\%28ISSN\%291098-111X>. Open Access Version: <http://kuscholarworks.ku.edu/dspace/>.

'usefulness', and the IQ model needs to account for uses that do not require a decision. Wang et al. $^{2}$ subsume relevance under the dimension of usefulness. However, as mentioned above, usefulness is an inappropriate label, or is placed at the wrong level in their model, as it seems unlikely that information could be inaccessible or unintelligible and still useful.

Relevance has many possible domain- and purpose-related criteria (e.g. 'materiality' and the cost-benefit relationship of Financial Accounting Standards Board ${ }^{1}$ ), but in all cases we require that information be of an age (relative to its volatility) such that we would still find it useful. Information that is too dated is irrelevant and useless. This consistent criterion is an important sub-attribute of 'Relevance' as discussed below. Wang et al. ${ }^{2}$ treat age and volatility of the information separately from 'relevance', under the criteria 'timeliness'. But, while irrelevant information could certainly meet the user's age requirements for a given volatility, the reverse (remaining relevant while failing volatility-relative age requirements) seems unlikely. Thus the criteria are not separable.

An additional meaning of 'timeliness'" is whether information, relevant or not, was available in time to be useful. Since this aspect of information quality is already captured in 'Accessibility', we instead use the term 'datedness'. Information datedness varies directly with its age and volatility.

Age measures how long ago information was recorded. All other things being equal, the more recently the information was recorded, the less likely it is to be dated, and the more likely it is to be relevant. For example, a doctor may require their recovering surgery patient to only have twice-daily blood pressure measurements, even though the underlying value varies continuously. Every twelve hours, the prior blood pressure measurement becomes dated information. If the next measurement is not made on time, the most recent (i.e. least dated) may suffice. Measurements from a week ago, however, are certainly too dated to be of acceptable quality.

Volatility of information is a measure of information instability - the frequency of change of the value for an entity attribute of interest (the 'source value'). The more volatile information is, the more rapidly any recorded value becomes dated and less relevant. Non-volatile information is stable; it does not change nor become dated. Again, for blood pressure, the underlying value varies from moment-to-moment (high volatility) and, in surgery, must be 
Srivastava, Rajendra. (2003) A Conceptual Framework and Belief-Function Approach to Assessing Overall Information Quality. International Journal of Intelligent Systems, 18 (1), 51-74. Publisher's Official Version: <http://onlinelibrary.wiley.com/journal/ 10.1002/\%28ISSN\%291098-111X>. Open Access Version: <http://kuscholarworks.ku.edu/dspace/>.

monitored continuously to provide high-quality information on patient status. For surgical purposes a one-day-old blood pressure measure would be irrelevant. But, for an annual physical exam, such a measure may be considered current.

Theoretically, all information could be recorded and reported as frequently as the source values changed and thus never become dated. However, this may not be necessary nor ideal for the user's purposes, let alone practical, feasible or cost-effective. So, datedness becomes an important IQ sub-attribute, with its value determined by the user's judgment of whether information is recent enough to be relevant, given the rate of change of the source value, and the user's domain and purpose of interest.

Since information may be relevant, but inaccessible or unintelligible, we use relevance as the dimensional label, and datedness as a consistent, specific, user-determined relevancy criterion among the many possible. This matches the organization of relevance and timeliness as factors important to Contextual Quality in the empirical model by Wang \& Strong ${ }^{3}$. The more dated information is, the less likely it is to be relevant to the user. The less relevant it is, the lower its quality. Once the 'what' and 'why' bounds on the desired information and its pieces are established through Relevance, we then wish to assess the associated values using some criteria.

\section{Integrity}

Last, we therefore argue that given access to interpretable, relevant information we require it to have integrity. In essence, 'Integrity' implies freedom from defects or flaws, or having the state of being unimpaired or sound. In our model (see Figure 1) integrity consists of the following four sub-attributes: accuracy, completeness, consistency and existence. Some researchers (e.g. see Nayer ${ }^{31}$, Wang et al. ${ }^{2}$, and Wang and Strong ${ }^{3}$ ) have not explicitly included the sub-attribute existence in the definition of 'Integrity' or its equivalent. We elaborate on existence later in the paper.

Wang et al. ${ }^{2}$ describe a similar set of sub-attributes, including 'credibility' (Figure 2), under the attribute 'believability.' Wang and Strong ${ }^{3}$ also group 'reputation' and 'believability' as 'intrinsic' attributes. As mentioned earlier, 'credibility' and 'believability' are circular, and given a reputable, credible or believable source, evidence of integrity attributes - accuracy, completeness, consistency and existence of the information - may be assumed, not evaluated. 
Srivastava, Rajendra. (2003) A Conceptual Framework and Belief-Function Approach to Assessing Overall Information Quality. International Journal of Intelligent Systems, 18 (1), 51-74. Publisher's Official Version: <http://onlinelibrary.wiley.com/journal/ 10.1002/\%28ISSN\%291098-111X>. Open Access Version: <http://kuscholarworks.ku.edu/dspace/>.

Though important to information users, credibility or reputation of an information source is evidence attesting to IQ integrity, not an information attribute, and may be evaluated without ever examining the information itself. Similarly, system security - prevention of unauthorized information access during storage and transmission ${ }^{10}$ - serves as evidence integrity has been maintained. Such judgments should enter the model as evidence in support of integrity rather than as sub-attributes that compose it and are therefore not included in our model.

Several IQ models have categorized various integrity criteria under dimensions other than the intrinsic nature of information ${ }^{3,8}$. This may stem from confusion between information attributes and users' definition and subsequent judgments of those attributes once fitness for use is established as the global quality standard, or from the substitution of terms such as "relevant" for "useful" in everyday speech. We distinguish here, for example, between critical or gross numbers of flaws in any Integrity sub-attribute (e.g. supplying a surgeon all the necessary and correct pre-operative clinical information for the wrong patient) and flaws in Relevance (supplying the surgeon the correct patient's nutritional or payment history). In each case the information is of low IQ and probably useless. Confusion may stem from casual reference to the first case (a critical accuracy flaw) as "irrelevant", and the latter case (a gross relevance flaw) as "completely inaccurate". To continue the earlier database analogy, once we have defined the structure of a desired table of records and their fields (Relevance), we need to define the criteria for their contained values (Integrity). For example, 'completeness' has to be defined by what the user considers complete information. If a recently graduated geriatrics specialist wants to establish a practice in a city and needs to have mailing addresses of people older than fifty, a database of addresses without this age group is not complete for the purpose of that doctor. As used herein, intrinsic attributes relate to the ability of information to map back to the conceptual or real-world thing of interest to the user (Integrity), while extrinsic attributes relate to the ability of information to map to the users' constructs, such as domain and purpose of interest (Relevance) and understandability or meaningfulness (Interpretability). However, it is important to note that Relevance determines the criteria for evaluating intrinsic attributes of IQ.

The first sub-attribute of 'Integrity' in our model is 'Accuracy', which refers to information being true or error free with respect to some known, designated or measured value. As part of a patient examination, the patient's name may be known and therefore comparable for accuracy to 
Srivastava, Rajendra. (2003) A Conceptual Framework and Belief-Function Approach to Assessing Overall Information Quality. International Journal of Intelligent Systems, 18 (1), 51-74. Publisher's Official Version: <http://onlinelibrary.wiley.com/journal/ 10.1002/\%28ISSN\%291098-111X>. Open Access Version: <http://kuscholarworks.ku.edu/dspace/>.

information that should contain it. The patient's identification number is designated and may be checked for accuracy against the algorithm or context from which it was derived. Lastly, the patient's blood pressure can be measured directly to determine if the recorded value and the measurement are the same or sufficiently close. Accuracy plays a major role in most models of IQ (e.g. Wang et al. ${ }^{2}$ ) as an intrinsic attribute of information. Yet without a standard, establishing accuracy is difficult (if not impossible in many circumstances), and what is acceptable or desirable information accuracy still requires judgment on the part of the user.

The second sub-attribute of 'Integrity' in our model is 'Completeness' which refers to having all required parts of an entity's information present (Wang et al. ${ }^{2}$, and Wang et al. ${ }^{15}$ ). A patient's report may typically require descriptive patient information such as name, age, sex, treatment and payment details, plus the results of various visit-specific tests and any pertinent diagnoses. Absence of any of these renders the report incomplete unless there is tolerance for missing values for some attributes. In a database environment, completeness can be in violation if a patient or patients' records are missing or certain field values are missing.

The third sub-attribute of 'Integrity is 'Consistency' of information, which requires that multiple recordings of the value(s) for an entity's attribute(s) be the same or closely similar across time or space (Wang et al. ${ }^{2}$, Strong, Lee and $\mathrm{Wang}^{8}$ ). These values must be the same in all cases (for discrete values) or closely grouped in dispersion (for continuous values). Although consistency appears frequently as a proposed quality dimension (Wang et al. ${ }^{15}$, Wand and $\mathrm{Wang}^{7}$ ), it does not appear as a prominent feature of empirically assessed user models of IQ. "Representational consistency" is used by Wang and Strong ${ }^{3}$, but in a manner to suggest subjective interpretability of formatting and display, not information integrity.

Hospitals often store information for different departments separately, and the records for a male admitted in one department and tested in another should both have the discrete value "Male" recorded for his gender. Having "Female" recorded in one would be both inaccurate in the single case, and inconsistent with all other sources. If this patient's blood pressure was measured once and recorded several places, it should be the same in all instances. The patient's blood pressure measurements taken several times at a single visit, or multiple times across departments on the same day, should be tightly dispersed. 
Srivastava, Rajendra. (2003) A Conceptual Framework and Belief-Function Approach to Assessing Overall Information Quality. International Journal of Intelligent Systems, 18 (1), 51-74. Publisher's Official Version: <http://onlinelibrary.wiley.com/journal/ 10.1002/\%28ISSN\%291098-111X>. Open Access Version: <http://kuscholarworks.ku.edu/dspace/>.

The fourth sub-attribute of Integrity is 'Existence', an important intrinsic attribute of information as used in auditing (e.g., see Mautz and Sharaf ${ }^{16}$ ). This sub-attribute has not been considered explicitly in any of the previous works. However, when one is providing assurance on information quality, not explicitly considering existence may lead to wrong conclusions about the information quality. Information that meets tests of 'Existence' has no false or redundant entities, fields, or attribute values. As mentioned earlier, the 'Existence' sub-attribute would be in violation if a database contains: 1) one or more records for patients that do not exist, 2) redundant records for certain patients, i.e., certain patient records are repeated, or 3) fictitious value(s) in certain field(s). Other than the conceptual model by FASB and their discussion of the need for validity and verifiability of information, no IQ model directly addresses all aspects of this problem. Wand \& $\mathrm{Wang}^{7}$ present a system-oriented model that most closely approximates this, discussing meaningless combinations of information (information not corresponding to the real world) and incorrect information (information wrongly mapping to the real world). However, fictitious information is not necessarily meaningless and can correspond to the real world. In fact, a goal of deliberately falsifying information is to undetectably simulate a realworld state that could have occurred, but did not. Another existence problem is redundancy. Redundant information is permissible in some systems models of IQ (Wand and Wang, 1996), and leads to ambiguity wherein at least one item of information should not exist, but it may be difficult to discern which is false. Establishing existence as a measure of integrity is an important auditing process.

Thus, our conceptual model of IQ (Figure 1) consists of three attributes (or assertions) that can be viewed as extrinsic to information: 'Accessibility', 'Interpretability', and 'Relevance', and one that can be viewed as intrinsic: 'Integrity.' Extrinsic attributes are determined by user perceptions of quality attributes and the intrinsic attribute. "Integrity', determined by inherent aspects of information, and with criteria that depend on user needs, consists of four sub-attributes (or sub-assertions): 'Accuracy', 'Completeness', 'Consistency', and 'Existence'.

\section{EVIDENTIAL NETWORK FOR ASSESSING IQ}

Srivastava and Mock ${ }^{18}$ developed an evidential network for WebTrust assurance services being provided by the American Institute of Certified Public Accountants (AICPA) and the Canadian Institute of Chartered Accountants (CICA)) for evaluating whether the service criteria 
Srivastava, Rajendra. (2003) A Conceptual Framework and Belief-Function Approach to Assessing Overall Information Quality. International Journal of Intelligent Systems, 18 (1), 51-74. Publisher's Official Version: <http://onlinelibrary.wiley.com/journal/ 10.1002/\%28ISSN\%291098-111X>. Open Access Version: <http://kuscholarworks.ku.edu/dspace/>.

have been met. The Srivastava and Mock $^{18}$ model augments the AICPA/CICA approach and provides goals, sub-goals and evidence relevant to the overall assurance. They consider the following four principles: 'Business Practice', 'Transaction Integrity', 'Information Protection', and 'Legal Environment'. The assurance provider collects and aggregates all evidence pertinent to the goals and sub-goals to determine the overall level of confidence that all the principles are met. Since all evidence collected in the process provides only partial support for the goals and sub-goals, they use the belief-function approach of Srivastava and Shafer ${ }^{19}$ to represent uncertainties (see Appendix A for a brief introduction to belief functions). If the evidence gathered in the process provides a sufficiently high level of overall confidence (say, 0.95 on a scale of $0-1)$ that WebTrust criteria are met, the assurance provider could issue an unqualified (i.e., clean) opinion on the service.

Srivastava et al. ${ }^{17}$ apply a similar evidential network-approach in the audit process of a healthcare unit. There are basically three issues in such approaches. First is the determination of relationships among the variables (i.e., assertions or sub-assertions) in the network. Second is the structure of the evidential network, which in essence requires the knowledge of what piece of evidence relates to what assertion or assertions. The network structure arises due to the fact that one item of evidence may pertain to more than one assertion or sub-assertion. The third issue deals with the representation of uncertainty involved in the judgment of whether a certain variable or attribute is met, at what level of confidence, based on the evidence collected. The first issue really deals with understanding the problem at hand. In other words, one needs to know the main variables (assertions or attributes) of the network and their interrelationships. In our case, the attributes that determine the quality of information are given in Figure 1.

Figure 2 represents an evidential network for IQ measurement. The rounded nodes represent variables in the network. These variables are: "Information Quality" (IQ), the extrinsic and intrinsic attributes $\mathrm{AI}_{1} \mathrm{RI}_{2}$ (Accessibility, Interpretability, Relevance, and Integrity), the components of Relevance: 'Datedness' and 'User-specified criteria', and the components of Integrity: 'Accuracy', 'Completeness', 'Consistency', and 'Existence'. The circle with '\&' inside it represents an 'and' relationship between the variable on the left of it with the variables on the right. For example, the main variable 'IQ' is connected to the four variables $\mathrm{AI}_{1} \mathrm{RI}_{2}$ on the right through an 'and' relationship. This implies that IQ is met (i.e., IQ is high) if and only if all 
Srivastava, Rajendra. (2003) A Conceptual Framework and Belief-Function Approach to Assessing Overall Information Quality. International Journal of Intelligent Systems, 18 (1), 51-74. Publisher's Official Version: <http://onlinelibrary.wiley.com/journal/ 10.1002/\%28ISSN\%291098-111X>. Open Access Version: <http://kuscholarworks.ku.edu/dspace/>.

the variables on the right are met (i.e., each has a high level of confidence that it is met). If any one of them is not met (i.e., it takes a low value) then IQ is not met (i.e., IQ is low).

--- Figure 2 here ---

The rectangular boxes represent items of evidence pertinent to various attributes as represented by direct linkages between items of evidence and the attributes. In order to determine the overall quality of information, one needs to gather the relevant items of evidence as indicated in Figure 2, evaluate the level of support each item of evidence provides to the corresponding variable(s), and then aggregate these assessments of support in the network to determine the overall level of support for the value 'high quality' of IQ. Below we describe two possible, important scenarios for assessing the overall level of support for IQ.

\section{SENSITIVITY ANALYSES}

Concern exists about the quality of online information (e.g. Silberg et al. ${ }^{12}$, Biermann ${ }^{11}$ ), where widespread availability and rapid access to information magnifies the potential for lowquality information to do harm (Office of Management and Budget, Executive Office of the President ${ }^{10}$ ). Compounding this, users of the information may lack the necessary access, resources or interest to evaluate the sub-attributes of Integrity described in Figure 1. Thus we pose an 'online-user' scenario in which overall IQ is evaluated only from support for IQ and for the attributes of Accessibility, Interpretability, Relevance and Integrity. In keeping with the inability of users to directly assess various aspects of online information quality, interest exists in online 'seals' that attest to various aspects of information ${ }^{32}$. Whether for online users or for purchasers of information products or related services, such assurance will require evaluation of the intrinsic attributes of information - Accuracy, Completeness, Consistency, and Existence. So, we also pose an 'assurance-provider' scenario in which support for IQ is aggregated from support for sub-attributes of Integrity and from proxy measures attesting to the evaluation of Accessibility, Interpretability and Relevance by the user(s).

Using a computer system known as Auditor's Assistant ${ }^{33}$, (see Appendix B for a brief description) for combining items of evidence in a network of variable s similar to Figure 2, where judgment of uncertainty is expressed under belief functions), we performed sensitivity analyses of the change in the belief that IQ is high for both scenarios (on-line user, and information 
Srivastava, Rajendra. (2003) A Conceptual Framework and Belief-Function Approach to Assessing Overall Information Quality. International Journal of Intelligent Systems, 18 (1), 51-74. Publisher's Official Version: <http://onlinelibrary.wiley.com/journal/ 10.1002/\%28ISSN\%291098-111X>. Open Access Version: <http://kuscholarworks.ku.edu/dspace/>

assurance provider) with regard to changes in the input beliefs that integrity is 'high' or 'low' using each of two relationships among the attributes - 'and' relationship and 'weighted average' relationship. An 'and' relationship requires each attribute of IQ to be met, i.e. true or 'high', for IQ to be of 'high' quality. Such a relationship makes sense, especially when all the attributes are essential in order for the main objective to be met. In contrast, under a user-centric view, varying degrees of importance might be placed on attributes or sub-attributes of IQ. Negation of attributes of IQ of little importance (e.g. Integrity of information for used solely for entertainment), may not, in this case, completely negate support for a high degree of overall IQ. Weighted averaging permits such a combination rule where the overall degree of belief that IQ is 'high' is equal to the weighted average of the beliefs of the individual attributes that are met. For example, suppose that the evidence collected suggests the following beliefs for each of the attribute: Belief that 'Accessibility' is high is 0.9, 'Interpretability' is high is 0.95, 'Relevance' is high is 0.9 , and 'Integrity' is high is 0.95. If each attribute is equally important then the 'weighted average' relationship would yield a total of belief of $0.925(=(0.9+0.95+0.9$ $+0.95) / 4$ ) that IQ is 'high'. However, one can show that under 'and' relationship, the total belief based on the above information would be $0.731(=0.9 * 0.95 * 0.9 * 0.95)$.

\section{DISCUSSION OF RESULTS}

Figure 3 a shows the online-user scenario with an 'and' relationship between the attributes of IQ and overall IQ. In the figure, strong support exists for the belief that IQ is 'high', say 0.90, from prior experience, maximal support exists for the belief that Accessibility is 'high', i.e., 1.0, and moderately strong support exists for the beliefs that Interpretability and Relevance are 'high', say 0.80. The assigned belief value that Integrity is high was varied from maximal (1.0) down to nil (0). As shown, with strong support for IQ being 'high', reduced belief in Integrity (or any other single attribute of IQ) being 'high' has little impact on the resulting overall belief that IQ is 'high'. Thus without any negative evidence (i.e. lack of support for an attribute being rated as 'high' but no support for the attribute being rated as 'low'), using 'and' logic the model is dominated by the support for IQ.

Figure $3 b$ depicts the same scenario, relationship between IQ and its attributes, and beliefs obtained from prior experience (evidence pertaining directly to IQ, see Figure 2), Accessibility, Interpretability, and Relevance. However, the varied belief value for Integrity is that of Integrity 
Srivastava, Rajendra. (2003) A Conceptual Framework and Belief-Function Approach to Assessing Overall Information Quality. International Journal of Intelligent Systems, 18 (1), 51-74. Publisher's Official Version: <http://onlinelibrary.wiley.com/journal/ 10.1002/\%28ISSN\%291098-111X>. Open Access Version: <http://kuscholarworks.ku.edu/dspace/>

being low - negative evidence. Proportional increases in belief that integrity is 'low' sharply decrease the overall belief in IQ being 'high' even with strong support for IQ being 'high' from prior experience. Also, whereas in Figure 3a there is no support for a belief in IQ being low, here the overall support for the belief that IQ is low sharply rises when belief in Integrity being low increases beyond 0.6 .

As an example (if a persons' aggregation of beliefs were to follow the model above), in the absence of evidence to the contrary, a pre-existing belief that the quality of online information is high may dominate lack of evidence or comfort that one of the attributes of IQ is 'high'. However, should evidence or belief exist that one of the IQ attributes is 'low' this may rapidly erode belief in IQ being 'high'. In short, if the user finds evidence to support the belief that one or more attributes of IQ are of low quality, the overall belief that IQ is of high quality reduces to a low value even though general reports, assurances, or prior experience suggest that online information is of high quality.

An undesirable behavior of 'and' logic is the attenuation of accumulated overall beliefs. In the absence of support from prior experience for IQ being 'high', strong beliefs (0.9) in Accessibility, Interpretability, Relevance and Integrity each being 'high' result in an overall IQ of 0.656. This effect (with different initial values) can also be seen in Figure 5, the assurance provider with 'and' logic scenario.

Figure $4 \mathrm{a}$ shows the results of the online- user scenario with weighted averaging applied to aggregate overall IQ. Again, very strong support from prior experience exists for the belief that IQ is 'high', say 0.90, maximal support exists for the belief that Accessibility is 'high' i.e., the belief is 1.0, and moderately strong support exists for the beliefs that Interpretability and Relevance are 'high', say 0.80 . The assigned belief value that Integrity was high was varied from maximal (1.0) down to nil (0). As illustrated, the resulting overall belief in IQ being 'high' is, of course, again dominated by the support for IQ from prior experience. Reducing belief in Integrity being 'high' to nil has little effect on the weighted average value of the overall belief that IQ is 'high'. Figure 4a also illustrates a potential drawback of the weighted average relationship resulting values are in a much more compressed range and the model is thus insensitive to gross decreases in individual or collective levels of assigned comfort, and lack of quality in attributes does not negate overall IQ. As illustrated in the Figure, decreased belief in Integrity being 'high' 
Srivastava, Rajendra. (2003) A Conceptual Framework and Belief-Function Approach to Assessing Overall Information Quality. International Journal of Intelligent Systems, 18 (1), 51-74. Publisher's Official Version: <http://onlinelibrary.wiley.com/journal/ 10.1002/\%28ISSN\%291098-111X>. Open Access Version: <http://kuscholarworks.ku.edu/dspace/>.

down to the level of zero barely impacts the overall rating of IQ, especially when the support from prior experience for IQ being 'high' is strong (0.9 in the present case).

Figure $4 \mathrm{~b}$ depicts the same scenario as Figure $4 \mathrm{a}$, but examines the impact of negative evidence. That is, the belief that Integrity is low is varied from nil (0) to maximal (1.0). As with Figure $4 \mathrm{a}$ there is little impact on the overall belief that IQ is 'high'. Introducing negative evidence yields some belief in IQ being 'low' and that, too, changes little as belief in Integrity being 'low' increases. Again, the resulting values being in a tightly compressed range. A more undesirable result of the weighted averaging method is that increased negative belief (increased belief in Integrity being 'low') has little effect on the overall rating of IQ.

Figure 5 shows the assurance provider scenario in which no support for IQ from prior experience is available. We assume ability on the part of the user to assess Accessibility, Interpretability and Relevance, and as assurance providers we must accumulate beliefs from critical sub-attributes of IQ to derive an overall IQ measure using 'and' logic. As in previous examples, maximal support exists for the belief that Accessibility is 'high', i.e., the belief is 1.0, and moderately strong support exists for the beliefs that Interpretability and Relevance are 'high', say 0.80 . The assigned belief value that each Integrity sub-attribute was high was varied from nil support (0) up to maximal support (1.0). As the figure illustrates, a principle problem with the behavior of the model under these conditions is the attenuation of the overall measure. With all base evidence for Integrity providing extremely strong levels of belief (0.9) that all subattributes are 'high,' the overall belief in IQ being 'high' is 0.420 . Even with evidence for only one Integrity sub-attribute providing a level of belief of 0.9 , and all other Integrity sub-attribute evidence providing belief levels of 1.0, the overall belief in IQ being 'high' is still only .567 . This problem would be compounded in the (likely) case that there were many user-specified criteria under Relevance. In addition, the overall belief in IQ being 'high' varies exponentially with simultaneous, parallel changes in all the beliefs in Integrity sub-attributes being 'high'. This causes the overall belief in IQ being 'high' to be extremely sensitive to such changes in the range where strong support exists. For example, a decrease from 0.95 to 0.90 in all beliefs that Integrity sub-attributes are high will cause a decrease from 0.52 to 0.42 in the overall belief that IQ is 'high' Changes to only one Integrity sub-attribute, however, causes linear changes in the overall 
Srivastava, Rajendra. (2003) A Conceptual Framework and Belief-Function Approach to Assessing Overall Information Quality. International Journal of Intelligent Systems, 18 (1), 51-74. Publisher's Official Version: <http://onlinelibrary.wiley.com/journal/ 10.1002/\%28ISSN\%291098-111X>. Open Access Version: <http://kuscholarworks.ku.edu/dspace/>.

belief in IQ being 'high' (e.g. a decrease from 0.95 to 0.90 in the belief that Accuracy is 'high' will result in a decrease in the overall belief in IQ being 'high' from 0.61 to 0.58 ).

Figure 6 shows the same assurance provider scenario and belief values using a weighted average relationship. Weighted averaging prevents some of the attenuation in overall IQ value that is seen when employing 'and' logic. However, again, weighted averaging is insensitive to gross decreases in beliefs assigned to individual sub-attributes. We should expect that in the absence of evidence in support of Integrity, ignorance about one of its sub-attributes (e.g. Accuracy) should decrease the belief in Integrity and therefore in overall IQ. However, reducing belief in support for one such Integrity sub-attribute, such as Accuracy, being 'high' to nil (0) has little effect on the overall IQ, reducing it from 0.9 to 0.84 in the example shown.

To summarize the sensitivity analyses, 'and' logic presents behavior that has theoretical face validity, and that may have some relationship to users' beliefs about IQ when negative evidence exists. When prior support exists that IQ is 'high', IQ values are maintained when support for attributes of IQ being 'high' is low or absent. Support for any attributes of IQ being 'low', however, rapidly erodes overall IQ values. In the absence of any prior support for IQ being 'high', one or more weak belief values for an IQ attribute being 'high' will strongly decrease the aggregate belief that IQ is 'high'. However, 'and' logic also attenuates strong beliefs in all IQ attributes being 'high' (e.g. placing values of 0.90 each on Accessibility, Interpretability, Relevance and Integrity results in an aggregate IQ value of 0.66), which may not satisfactorily represent users' aggregation of beliefs about IQ. Weighted averaging eliminates this problem of attenuation found with 'and' logic, however it is insensitive to gross decreases in individual or collective levels of belief that IQ attributes are 'high', regardless of whether support for IQ being 'high' exists. Neither algorithm alone is satisfactory. In addition, the algorithms and their results are only intuitively evaluated here. Testing of the logical implementations and behavior of the network under various algorithms needs to be compared to how information users assess IQ.

\section{SUMMARY, CONCLUSION AND DIRECTIONS FOR FUTURE RESEARCH}

The modified IQ model presented here extends and bridges previous models, resolving ambiguities in terminology and relationships of quality attributes. In particular: judgments of 
Srivastava, Rajendra. (2003) A Conceptual Framework and Belief-Function Approach to Assessing Overall Information Quality. International Journal of Intelligent Systems, 18 (1), 51-74. Publisher's Official Version: <http://onlinelibrary.wiley.com/journal/ 10.1002/\%28ISSN\%291098-111X>. Open Access Version: <http://kuscholarworks.ku.edu/dspace/>.

information source credibility and system security exist independently of information attributes and must therefore enter from outside any information model; 'believability' and 'credibility' cannot be independent quality attributes nor an attribute and related sub-attribute as they are circularly related; 'credibility' is replaced in the model by 'integrity', a global assessment based on one or more judgments and belongs at a high level within the quality model; information datedness is a consistent attribute of relevance to the user, not independent from relevance; and, although aspects of it are found in systems-oriented data quality models, existence as found in auditing is an important concept absent in other IQ models. In our explanation of definitions we have also clarified a potentially critical ambiguity in the definition of information by proposing that usefulness does not transform data to information, nor define a characteristic of information itself, but is a user-dependent judgment of IQ. This and the clarifications above provide the theoretical foundation for our modified model, which forms the structure for evidential network, to then be used to evaluate overall IQ.

The two scenarios presented ('online- user' and 'assurance-provider') reflect two likely and important aspects of IQ evaluation currently facing information users - concerns about poor quality online information, and the need for information quality assurance. The two algorithms ('and' logic and weighted average) tested in sensitivity analyses of the evidential network in each scenario display both desirable and undesirable behaviors. 'And' logic presents face validity with the theoretical logic that IQ support should be diminished or negated by the presence of support for any major attribute of IQ being 'low'. In addition, 'and' logic exhibits behavior similar to that of users placing optimistically high levels of belief in IQ due to strong evidence in support of IQ being 'high' from prior experience, yet drastically reversing their beliefs when support increases for any major attribute being 'low.' However, in the absence of evidence on IQ from prior experience, 'and' logic attenuates the overall assessment of IQ being 'high' when all major IQ attributes are rated as 'high' with strong levels of support. This makes it unsatisfactory for use when evaluating sub-attributes of IQ for assurance provision and counter-intuitive for use by online users with no preconceived belief in the inherent quality of online information. Weighted averaging prevents the above attenuation due to 'and' logic, but is insensitive to gross decreases in individual or collective levels of assigned comfort. Further research exploring algorithms with rules of combination that generate better-tempered behavior is warranted. 
Testing of the logical implementation and behavior of the network, however, needs to be supplemented with investigations of its applicability for information consumers (as it is designed as a user-centric model). We propose empirical evaluation of the network structure and attributes with information users' assessments of IQ. An immediate focus of future research will include testing the applicability of the model and its algorithms for clinical and Web information users and the attestation of information quality within these contexts.

In addition, applicability of the model requires evaluation through field-testing. Given the concerns about Internet information quality (health information in particular), the evidential network could be used for rating website IQ through an online interface and user feedback collected to evaluate the tool. One such IQ rating tool is available from MITRETEK ${ }^{34}$, but does not use belief functions to represent nor aggregate users' ratings. Discussed earlier, the belief function framework appears to better represent human judgments of real-world uncertainties.

Lastly, given the global explosion of information availability and the concerns about online information quality, we see a need for a robust IQ model expressed in XML. As bandwidth and processing speeds increase, a theoretically and practically proven IQ model holds promise as a taxonomy for metadata tags thatwould reduce the need for manual evaluations of IQ. We believe exploring the semantic consistency and validity of the model in a wider range of contexts, and for more complex information constructs (such as taxonomies) will facilitate that goal. 


\section{APPENDIX A}

\section{Introduction to Belief Functions}

The Belief-Function framework is a broader framework for representing uncertainty than probability. Essentially, under the probability framework, we assign probability mass, P, to each possible value of a variable where all such masses add to one. For example, suppose there are $n$ possible values, $a_{1}, a_{2}, \ldots a_{n}$, of variable A. Under the probability framework we assign probability mass to each value of the variable, i.e., $P\left(a_{i}\right) \geq 0$, such that $\sum_{i=1}^{n} P\left(a_{i}\right)=1$. However, under the belief-function framework, we assign uncertainty, represented by malues belief masses as referred by Smets ${ }^{35,36,37}$, and basic probability assignment function by Shafer ${ }^{38}$ ), to not only singletons but to all other possible subsets including the entire frame $\Theta=\left\{a_{1}, a_{2}, \ldots a_{n},\right\}$. In the above example this means: $m\left(a_{i}\right) \geq 0, m\left(\left\{a_{i}, a_{j}\right\}\right) \geq 0, m\left(\left\{a_{i}, a_{j}, a_{k}\right\}\right) \geq 0, \ldots m(\Theta) \geq 0$, where $i, j$, and $\mathrm{k}$ take values from $1 \ldots \mathrm{n}$, and $\mathrm{i} \neq \mathrm{j} \neq \mathrm{k}$, such that all such belief masses add to one, i.e., $\sum_{B \subseteq T} m(B)=1$. The Belief-function framework reduces to probability framework when the only non-zero $\mathrm{m}$-values are for the singletons.

Belief in a subset $\mathrm{B}$ of a frame $\Theta$ determines the total belief one has in $\mathrm{B}$ based on the evidence represented through $\mathrm{m}$-values. It is defined as $\operatorname{Bel}(B)=\sum_{X \subseteq B} m(X)$, where $X$ represents a set of elements of $\Theta$. Let us consider the following example for illustration. Suppose we have a mixed item of evidence pertaining to a specific piece of information being of 'high' or 'low' quality with the following distribution of belief masses: $\mathrm{m}($ high $)=0.6, \mathrm{~m}(\mathrm{low})=0.3, \mathrm{~m}(\Theta)=$ 0.1 , where $\Theta=\{$ high, low $\}$. These m values imply that, based on the evidence, we have 0.6 level of support that the information quality is high, 0.3 level of support that it is low, and 0.1 level of support that it is either high or low representing the ignorance. Based on the above example, the belief that the information is of high quality is $\operatorname{Bel}($ high $)=m($ high $)=0.6$, the belief that the information is of low quality is $\operatorname{Bel}($ low $)=\mathrm{m}(\mathrm{low})=0.3$, and the belief that the information is either of high quality or low is $\operatorname{Bel}(\{$ high, low $\})=m($ high $)+m($ low $)+m(\{$ high, low $\})=$ $0.6+0.3+0.1=1.0$. 
Plausibility in a subset $\mathrm{B}$ of a frame $\Theta$ defines the degree to which $\mathrm{B}$ is plausible in the light of the evidence. Mathematically, it is defined as: $\mathrm{Pl}(\mathrm{B})=\sum_{\mathrm{B} \cap \mathrm{X} \neq \varnothing} \mathrm{m}(\mathrm{X})=1-\operatorname{Bel}(\sim \mathrm{B})$, where $\sim \mathrm{B}$ represents the negation of $\mathrm{B}$ and $\mathrm{X}$ represents a set of elements in $\Theta$. For the above example, plausibility that the information is of high quality is $\mathrm{Pl}$ (high) $=0.6+0.1=0.7$, and plausibility that the information is of low quality is $\mathrm{Pl}(\mathrm{low})=0.3+0.1=0.4$. One can express complete ignorance or lack of opinion about $\mathrm{B}$ by $\mathrm{Bel}(\mathrm{B})=0$ and $\mathrm{Pl}(\mathrm{B})=1$ (e.g., see Srivastava and Shafer $\left.{ }^{19}\right)$.

Two or more items of evidence pertaining to a variable are aggregated using Dempster's rule of combination (Shafer, 1976). For two items of evidence Dempster's rule is defined as: $\mathrm{m}(\mathrm{B})=\sum_{\mathrm{B}=\mathrm{B}_{1} \cap \mathrm{B}_{2}} \mathrm{~m}_{1}\left(\mathrm{~B}_{1}\right) \mathrm{m}_{2}\left(\mathrm{~B}_{2}\right) / \mathrm{K}$, where $\mathrm{m}_{1}$ and $\mathrm{m}_{2}$ are the two belief masses pertaining to the frame $\Theta$ and $\mathrm{K}$ is the renormalization constant defined as: $\mathrm{K}=1-\sum_{\mathrm{B}_{1} \cap \mathrm{B}_{2}=\varnothing} \mathrm{m}_{1}\left(\mathrm{~B}_{1}\right) \mathrm{m}_{2}\left(\mathrm{~B}_{2}\right)$. The second term in $\mathrm{K}$ represents the conflict. Under the situation when two items of evidence completely conflict each other, i.e., $\mathrm{K}=0$, the two items of evidence are not combinable. Srivastava and Mock $^{39}$ provide a good introduction to belief functions in their book, Belief functions in Business Decisions ${ }^{40}$. 


\section{APPENDIX B}

\section{Introduction to Auditor's Assistant}

Srivastava et al. ${ }^{17}$ provide a detailed description of Auditor's Assistant (AA) along with its functionality. For the convenience of readers we provide a brief review of AA here. AA is decision-support software written in Pascal for the Apple Macintosh ${ }^{33}$. Originally described for decision-making in auditing, AA provides a graphic user interface to facilitate the construction of networks of evidence, variables and their logical relationships. Variables appear as rounded rectangles in the diagram and have multiple possible values. For example, elsewhere in the paper the variable Information Quality is described as having two possible values - 'high' and 'low'. The user can create relationships between variables under the belief-function framework. However, for ease of use AA has a built-in 'and' relationship represented by a circle with ' $\&$ ' in it. The 'and' relationship implies that the variable on the left is related through an 'and' relationship to all the variables on its right. Evidence appears as rectangles linked to the variables it pertains to. A network structure arises when one item of evidence pertains to more than one variable. The decision maker inputs the level of belief in terms of m values obtained from each piece of evidence pertaining to a variable. AA aggregates the evidential support in the diagram using

Shenoy and Shafer ${ }^{41,42}$ algorithms of local computation and Dempster's Rule ${ }^{38}$, yielding the overall belief at each variable. 
Srivastava, Rajendra. (2003) A Conceptual Framework and Belief-Function Approach to Assessing Overall Information Quality. International Journal of Intelligent Systems, 18 (1), 51-74. Publisher's Official Version: <http://onlinelibrary.wiley.com/journal/ 10.1002/\%28ISSN\%291098-111X>. Open Access Version: <http://kuscholarworks.ku.edu/dspace/>.

\section{REFERENCES}

1. Financial Accounting Standards Board. "Statement of Financial Accounting Concepts No. 2, Qualitative Characteristics of Accounting Information", Original Pronouncements, Accounting Standards as of June 1, 1993, Volume II (AICPA Pronouncements, FASB Interpretations, FASB Concepts Statements, FASB Technical Bulletins), Financial Accounting Standards Board, CN, USA, 1993.

2. Wang, R.Y., Reddy, M.P., and Kon, H.B. Decision Support Systems, 1995, 13, 349-372.

3. Wang, R.Y. and Strong, D.M. Journal of Management Information Systems, Spring 1996, Vol. 124, 5-34.

4. Neef, D.E. The Knowledge Economy, Butterworth-Heinemann, Boston, Massachusetts, USA, 1998.

5. Stonier, T. Journal of Information Science, 1991, 17(5), 257-263.

6. Huang, K-T., Lee, Y.W and Wang, R.Y. Quality Information and Knowledge, Prentice Hall, Upper Saddle River New Jersey, USA, 1999.

7. Wand, Y. and Wang, R.Y. Communications of the ACM, November 1996, 39(11), 86-95.

8. Strong, D.M., Lee, Y.W., and Wang, R.Y. Communications of the ACM, May 1997, 40(5), 103-110.

9. English, L. P. Improving Data Warehouse and Business Information Quality: Methods for Reducing Costs and Increasing Profits. John Wiley and Sons, Inc, New York, New York, USA, 1999.

10. Office of Management and Budget (OMB), Executive Office of the President, Guidelines for Ensuring and Maximizing the Quality, Objectivity, Utility, and Integrity of Information Disseminated by Federal Agencies, http://www.whitehouse.gov/omb/fedreg/final_information_quality_guidelines.html, October 21, 2001.

11. Biermann, J.S., Golladay, G.J, Greenfield, M.L.V.H. and Baker, L.H. Cancer, August 1999, 86(3), 381-390.

12. Silberg, W.M., Lundberg, G.D., and Musacchio, R.A. Aging and Information Technology, Fall 1997, 53-55.

13. Fox, C., Levitin, A. and Redman, T. Information Processing and Management, 1994, 30(1):9-19.

14. Lopes, Alexandre B., and Babbitt, T. "Knowledge Management: Differing Ideals, Differing IT Implications," Americas Conference on Information Systems, Milwauke, WI, USA, 1999. 
Srivastava, Rajendra. (2003) A Conceptual Framework and Belief-Function Approach to Assessing Overall Information Quality. International Journal of Intelligent Systems, 18 (1), 51-74. Publisher's Official Version: <http://onlinelibrary.wiley.com/journal/ 10.1002/\%28ISSN\%291098-111X>. Open Access Version: <http://kuscholarworks.ku.edu/dspace/>.

15. Wang, R.Y., Storey, V.C. and Firth, C.P. IEEE Transactions on Knowledge and Data Engineering, August 1995, 7(4), 623-639.

16. Mautz and Sharaf, Philosophy of Auditing, American Accounting Association, Sarasota, Florida, 1964.

17. Srivastava, R. P., Dutta, S. K., and Johns, R. International Journal of Intelligent Systems in Accounting, Finance and Management, 1996, Vol. 5, No. 3, 165-183.

18. Srivastava, R. P. and Mock, T. J. Journal of Management Information Systems, Vol. 10, No. 3, Winter 1999-2000, 11-32.

19. Srivastava, R. P., and Shafer, G. The Accounting Review, April 1992, 249-283.

20. Harrison, K., Srivastava, R.P., and Plumlee, R. D. “Auditors' Evaluations of Uncertain Audit Evidence: Belief Functions versus Probabilities," in Belief Functions in Business Decisions, edited by R. P. Srivastava and T. Mock, Physica-Verlag, Heidelberg, Springer-Verlag Company, 2002, 161-183.

21. Curley, S. P., and Golden, J. I. Organization Behavior and Human Decision Processes, 1994, $271-303$.

22. Shafer, G. and Srivastava, R.P. Auditing: A Journal of Practice and Theory, Supplement 1990, 110-148.

23. Davenport, T.H. and Prusak, L. Working Knowledge: How Organizations Manage What They Know, Harvard Business School Press, Boston, Massachusetts, USA, 1998.

24. Machlup, F. "Semantic Quirks in Studies of Information,” in The Study of Information: Interdisciplinary Messages, edited by F. Machlup and U. Mansfield, John Wiley \& Sons, NY, USA, 1983.

25. Redman, Thomas C., Data Quality For The Information Age, Artech House, Boston, 1996.

26. Deming, W. E. Quality, productivity and competitive position, Massachusetts Institute of Technology, Center for Advanced Engineering Study, Cambridge, Massachusetts, 1982.

27. Garvin, David A. Harvard Business Review, November-December, 1987, 101-109.

28. Juran, J. M. Juran on leadership for quality. Free Press, New York, 1989.

29. Kinney, Information Quality Assurance and Internal Control For Management Decision Making, McGraw-Hill Higher Education, Boston, Massachusetts, USA, 2000.

30. Lieberman, E. "Tres Ipsa Loquitor," keynote speech at MIT IQ Conference, Boston, Massachusetts, USA, 2000.

31. Nayer, M. Information Systems Management, 10(2), Spring 1993, 51-58. 
32. Johnson, Everett. "WebTrust, SysTrust and Beyond," Proceedings of the 2000 Deloitee \& Touche/University of Kansas Symposium on Auditing Problems, School of Business, The University of Kansas, Lawrence, Kansas, 2000.

33. Shafer, G., She noy, P.P. and Srivastava, R.P. Proceedings of the 1988 Touche Ross University of Kansas Symposium on Auditing Problems, May 1988, 61-79.

34. MITRETEK, Criteria for Assessing the Quality of Health Information on the InternetPolicy Paper, http://hitiweb.mitretek.org/docs/policy.html, 1999.

35. Smets, P. “The Transferable Belief Model For Quantified Belief Representation,” in Quantified Representation for Uncertainty and Imprecision, Vol. 1. Edited by P. Smets. Kluwer Academic Publishers, 1998.

36. Smets, P. "The Combination of Evidence in the Transferable Belief Model," in IEEE Transactions on Pattern Analysis and Machine Intelligence, 12, 5, May, 1990.

37. Smets, P. "Constructing the Pignistic Probability Function in a Context of Uncertainty," in Uncertainty in Artificial Intelligence 5. ed. by Henrion, M., Shachter, R.D., Kanal, L.N., and Lemmer, J.F. North-Holland: Elsevier Science Publishers, 1990.

38. Shafer, G. A Mathematical Theory of Evidence. Princeton University Press, 1976.

39. Srivastava, R.P. and Mock, T.J. "Introduction to Belief Functions," in Belief Functions in Business Decisions, edited by R. P. Srivastava and T. Mock, Physica-Verlag, Heidelberg, Springer-Verlag Company, 2002, 1-16.

40. Srivastava, R.P. and Mock, T.J. Belief Functions in Business Decisions, Physica-Verlag, Heidelberg, Springer-Verlag Company, 2002.

41. Shenoy, P., and Shafer, G. IEEE Expert, 1986, 1 (3), 43-52.

42. Shenoy, P., and Shafer, G. "Axioms for Probability and Belief-Function Propagation.," in Uncertainty in Artificial Intelligence, 4, edited by R. D. Shachter, T. S. Levitt, J. F. Lemmer, and L. and N. Kanal, North-Holland, 1990, 169-198. 
Table 1: Information Schools of Thought ${ }^{25}$.

\begin{tabular}{|l|l|}
\hline School & \multicolumn{1}{|c|}{ Perceptions } \\
\hline Information Management & Processed data \\
\hline Infological & Knowledge, information for decision making or action-taking \\
\hline Statistical & Relevant part or summary of data from an experiment \\
\hline Everyday Use & Message part that informs \\
\hline Information Theory & Uncertainty reduction \\
\hline Thermodynamic & Inverse of entropy \\
\hline
\end{tabular}


Figure 1: IQ Model Proposed in the Present Study

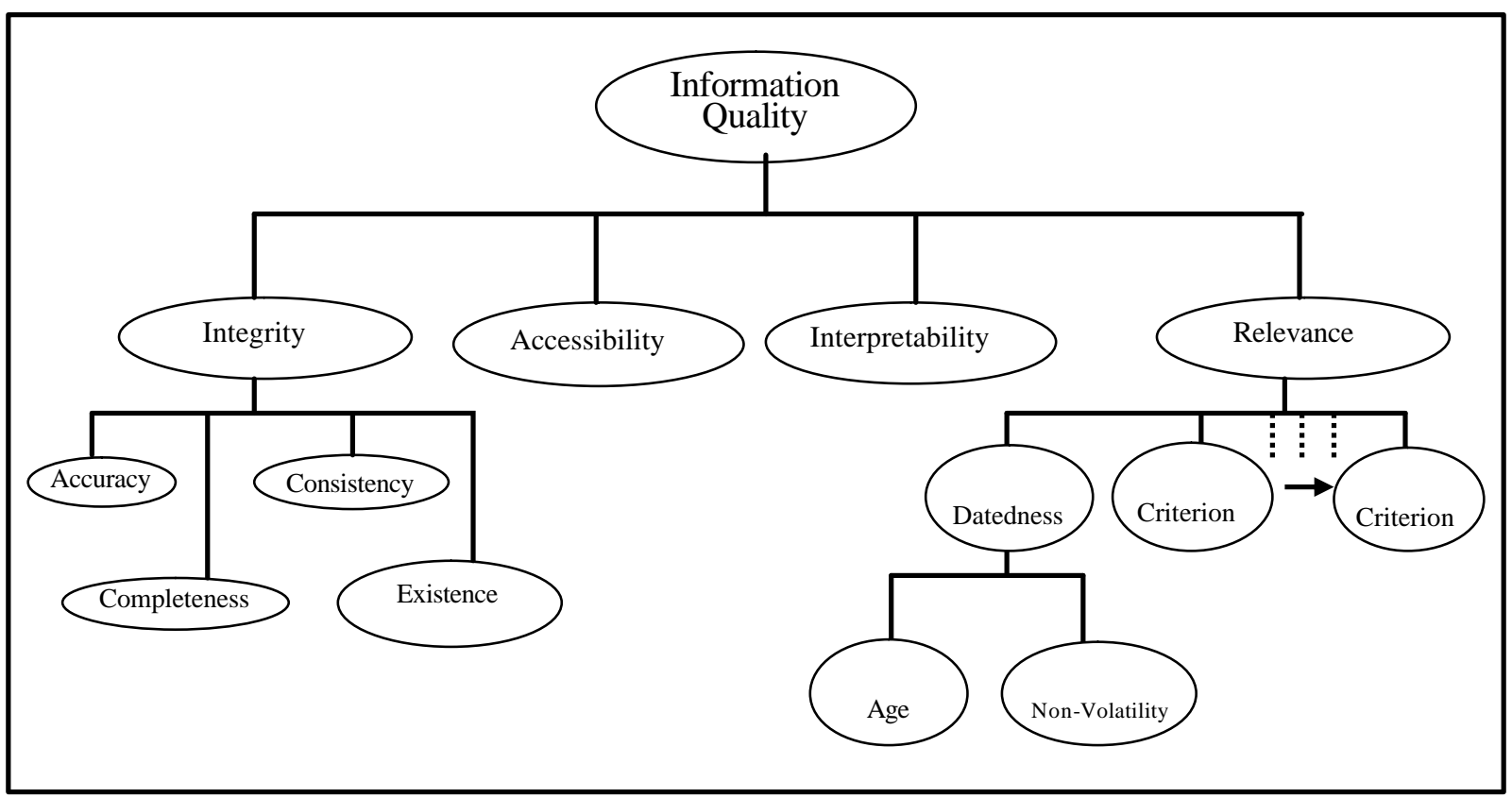

Figure 2: Evidential Network of Information Quality Attributes and Sub-attributes

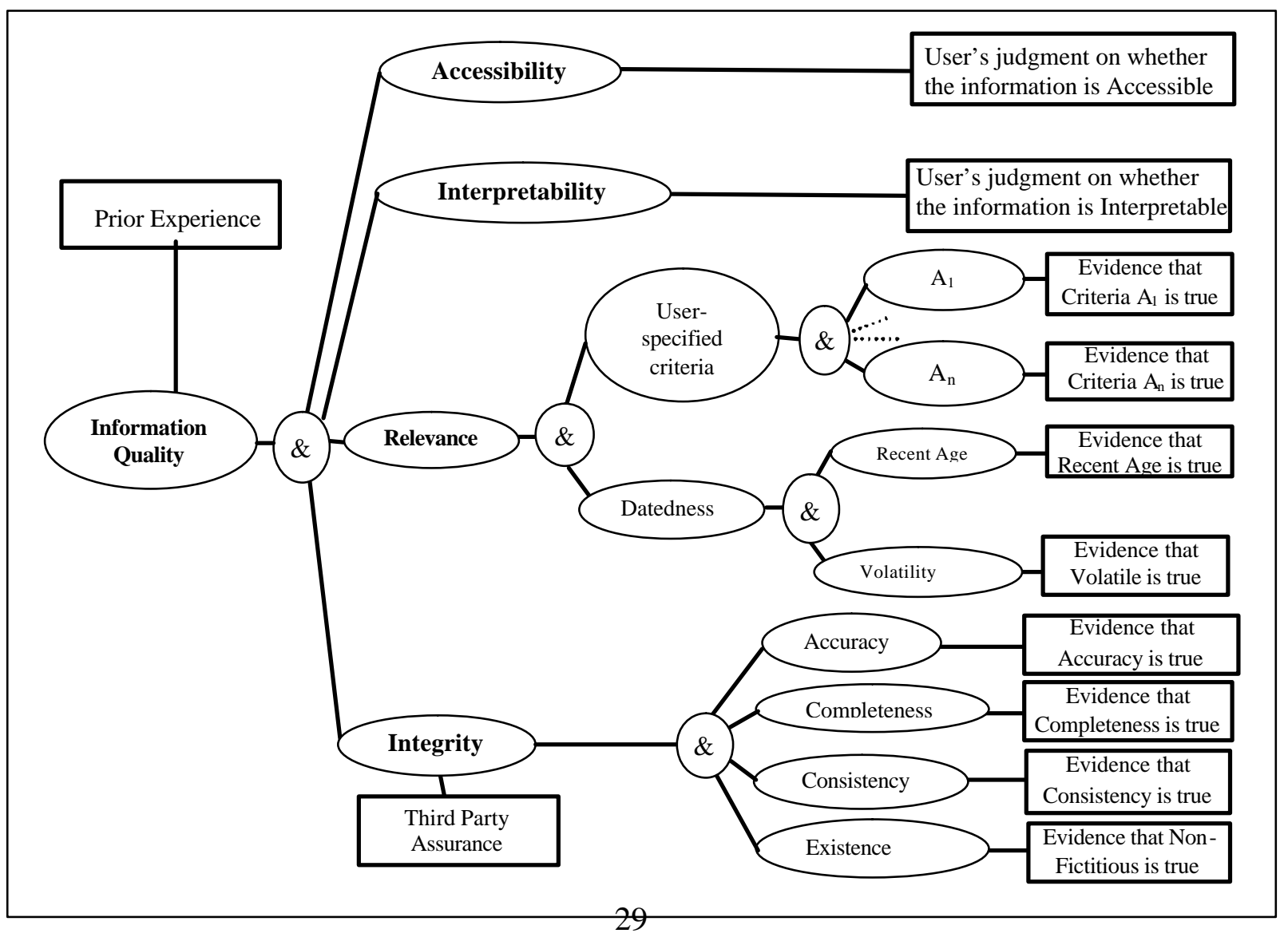


Figure 3a: Online User Scenario with 'and' logic, and varying beliefs for Integrity being 'high,' with a strong belief (0.9) that IQ is 'high', fixed values of beliefs that Accessibility (1.0), Interpretability (0.80) and Relevance are each 'high' (0.80).

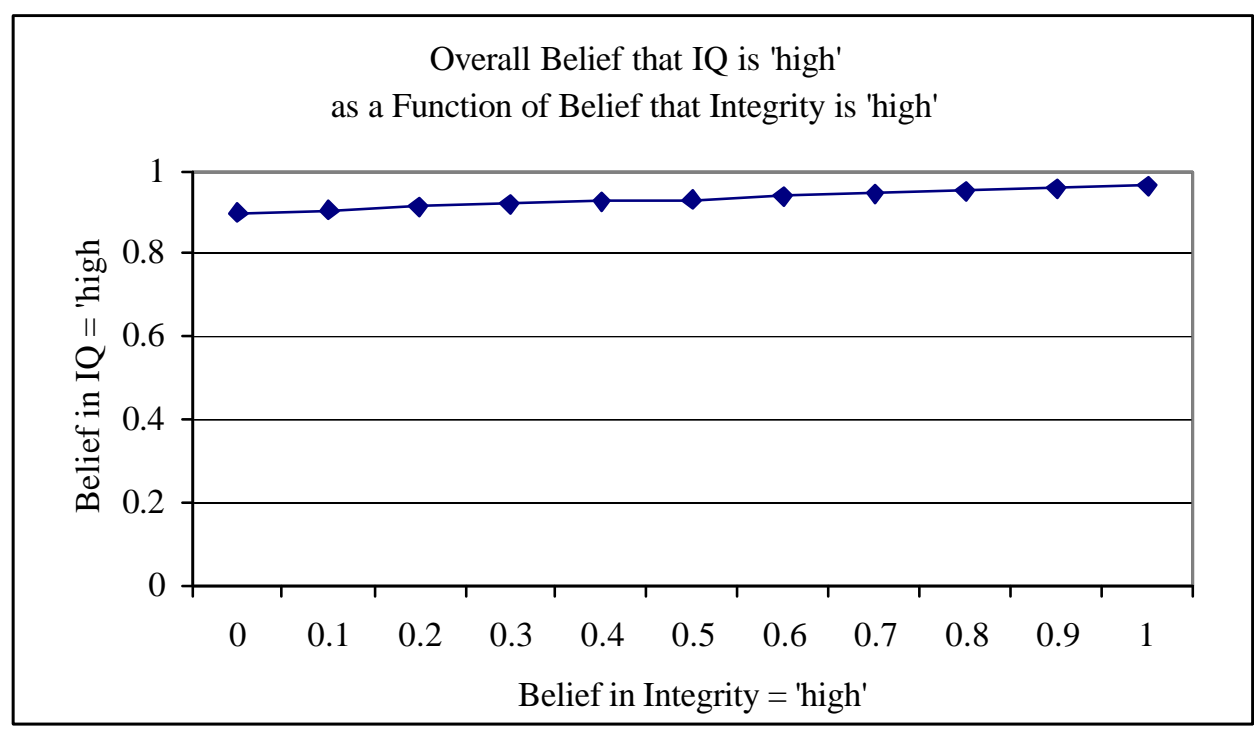

Figure 3b: Online User Scenario with 'and' logic, and varying beliefs on Integrity being 'low,' with a strong belief (0.9) that the overall IQ is 'high', fixed values of beliefs that Accessibility is 'high' (1.0), Interpretability is 'high' (0.80) and Relevance is 'high' (0.80).

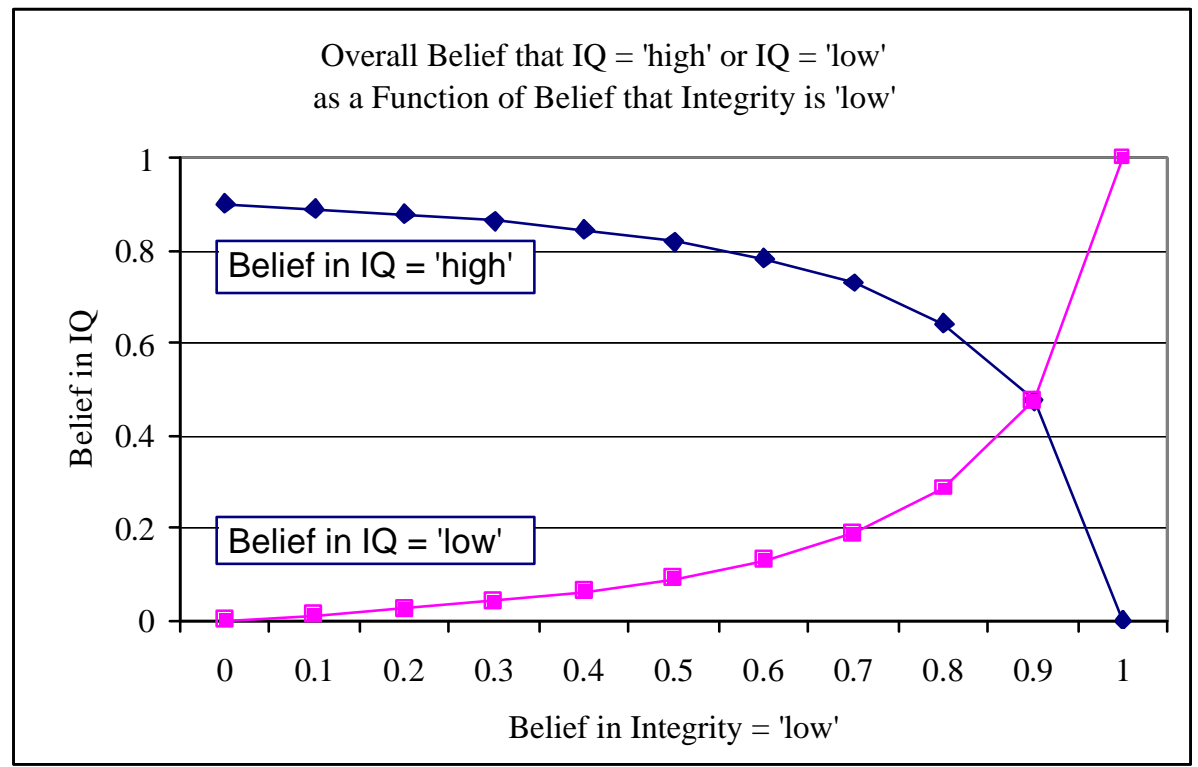


Figure 4a: Online User Scenario with Weighted Averaging and varying beliefs on Integrity being 'high,' with a strong belief (0.9) that the overall IQ is 'high', fixed values of beliefs that Accessibility is 'high' (1.0), Interpretability is 'high' (0.80) and Relevance is 'high' (0.80). Weighted averages were calculated as equally-weighted (i.e. ordinary) averages, these values propagated to the next node, and then combined using Dempster's Rule.

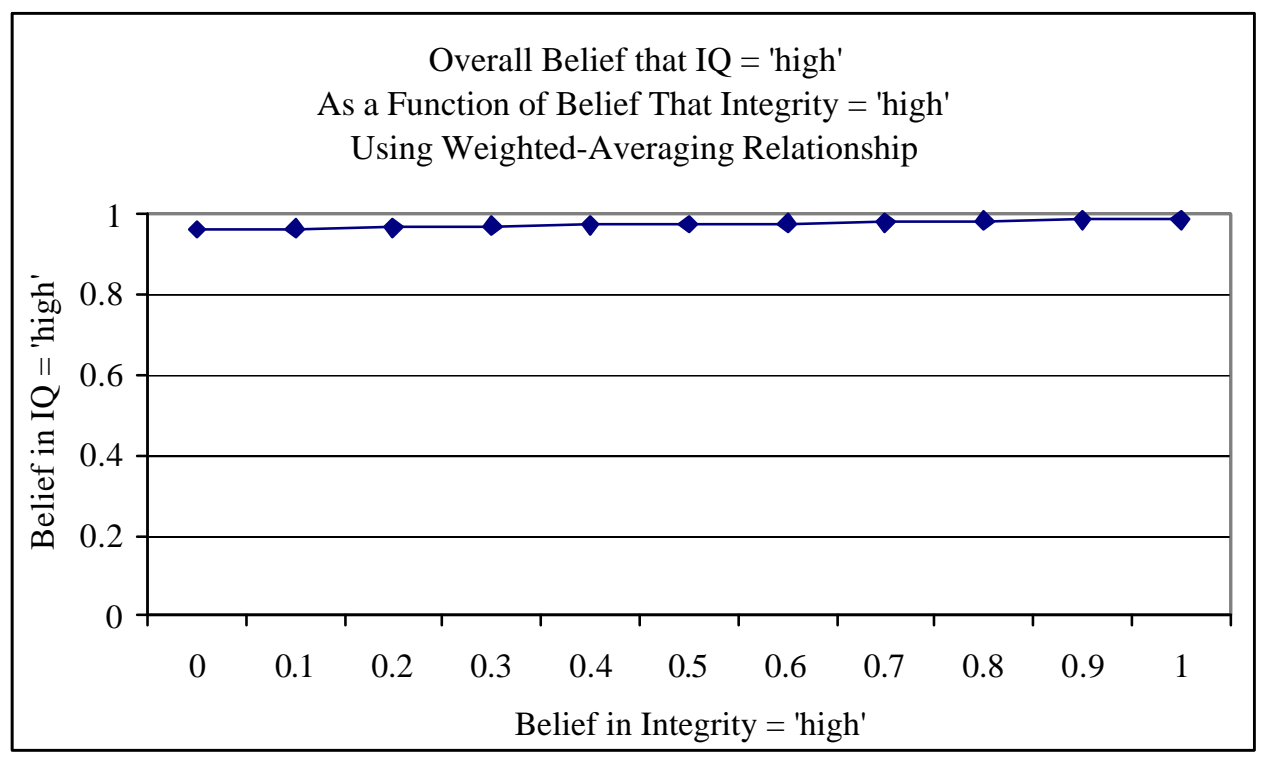

Figure 4b: Online User Scenario with Weighted Averaging and varying beliefs on Integrity being 'low,' with a strong belief (0.9) that the overall IQ is 'high', fixed values of beliefs that Accessibility is 'high' (1.0), Interpretability is 'high' (0.80) and Relevance is 'high' (0.80).

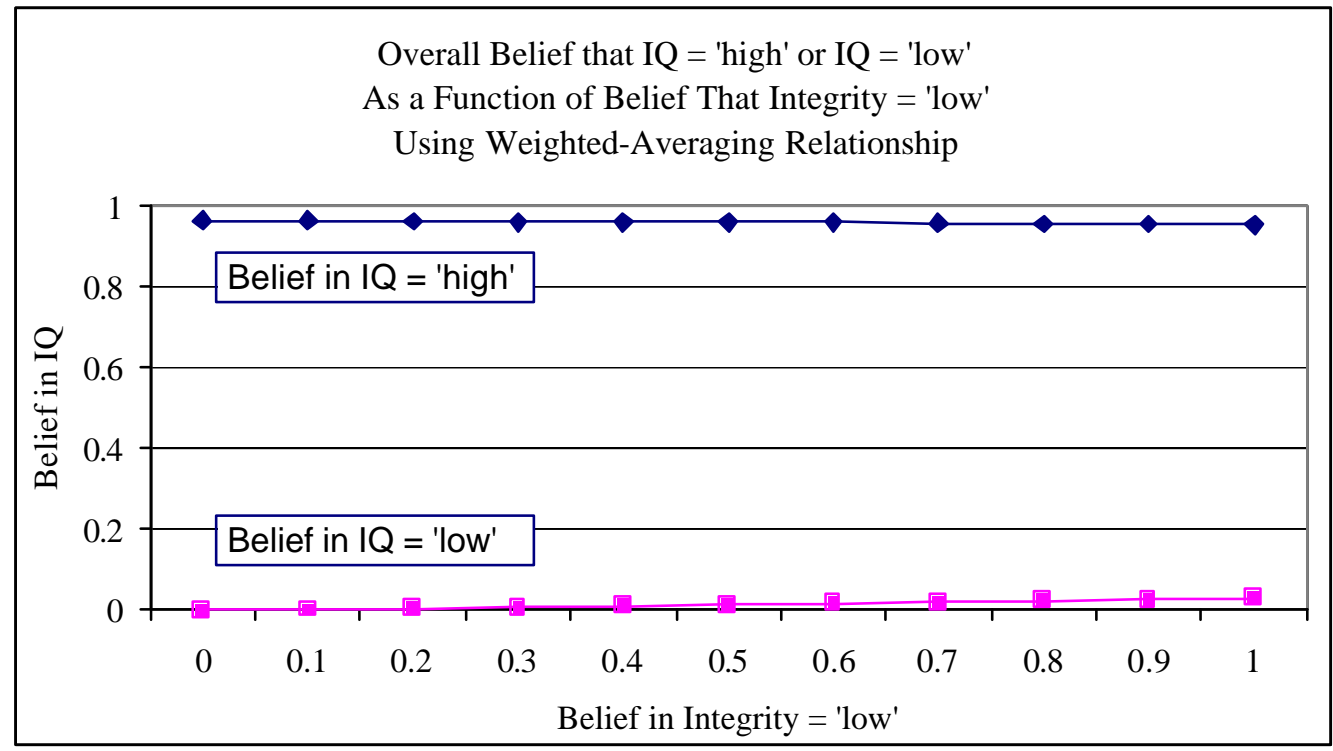


Figure 5: Assurance Provider Scenario with 'and' Logic, and Overall Belief that IQ is 'high' as a function of input beliefs that Integrity sub-attributes are 'high'.

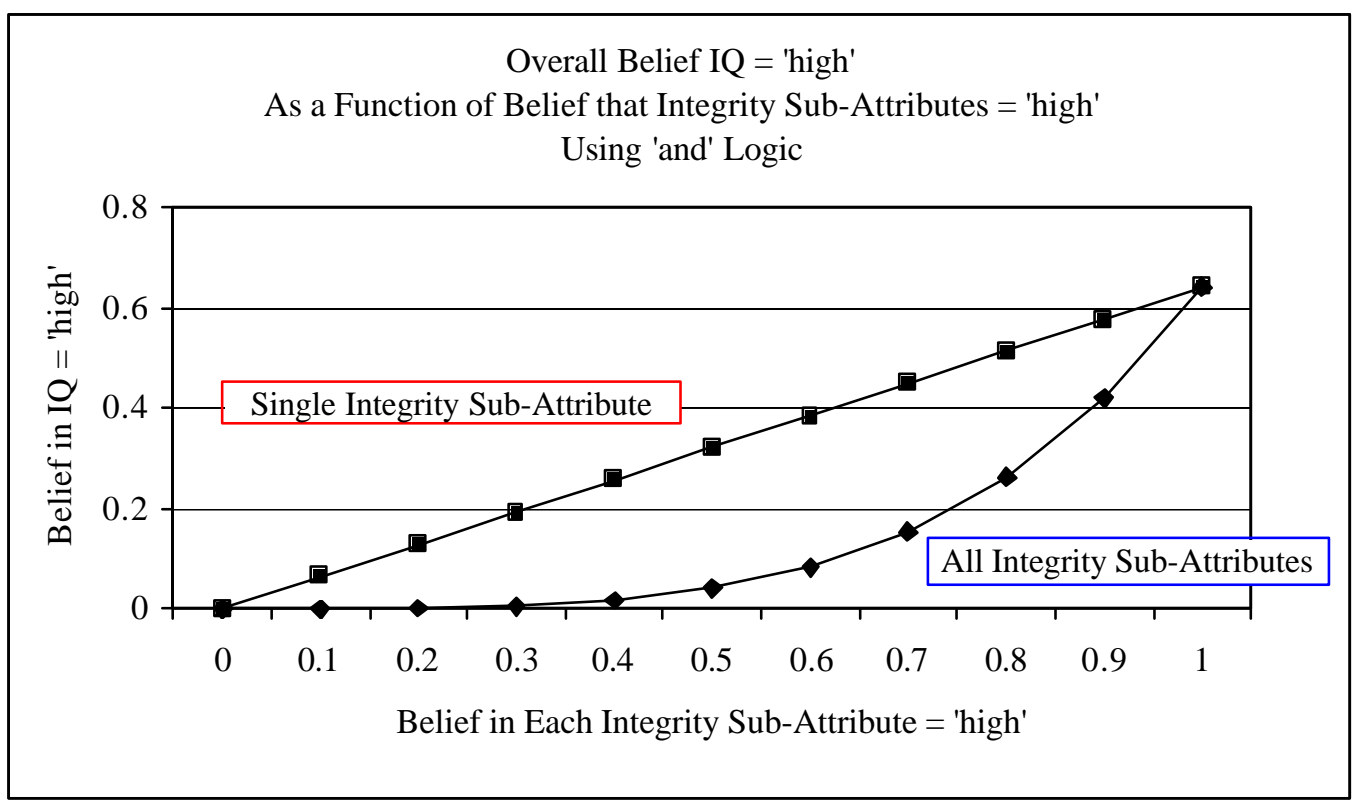

Figure 6. Assurance Provider Scenario with Weighted Averaging (WA) and overall belief that IQ is 'high' as a function of input beliefs that Integrity sub-attributes are 'high'.

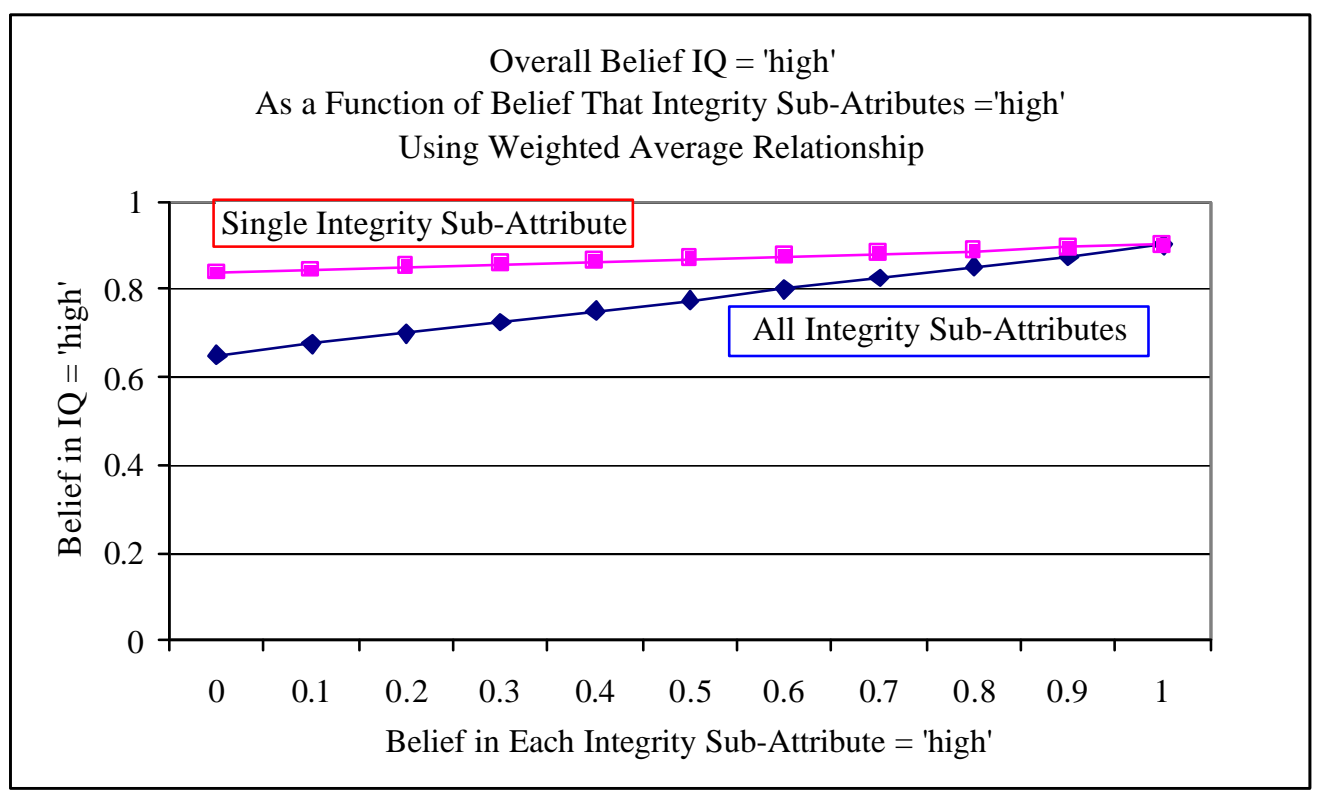

